\title{
Proyectos de limpieza social e imaginarios urbanos de la perfección.
}

\section{Social cleansing projects and urban imaginaries of perfection.}

Recibido: marzo/2018

Aceptado: agosto/2018

\section{Resumen}

El artículo trata sobre el desarrollo de las ideas sobre eugenesia y "purificación de la raza" y su relación con el diseño basado en ideas de perfección que persiguen las ciudades contemporáneas a través de la pretensión de ejercer un control en todos los aspectos de la vida de los ciudadanos. Se realizó una netnografía mediante el buscador Google para explorar sobre las imágenes que rodean a tales búsquedas de control y perfección de los escenarios de la vida y de los propios habitantes. Finalmente se reflexiona sobre los imaginarios que rodean a la búsqueda de una sociedad y una ciudad perfectas a través del mito de Hybris.

\section{Palabras Clave:}

Imaginarios urbanos; eugenesia; netnografía.
Dra. Gabriela Carmona Ochoa / UA de $\mathrm{C}^{1}$

Dr. Adolfo Benito Narváez Tijerina ${ }^{2}$ UANL $^{3}$

The article deals with the development of ideas about eugenics and "purification of the race" and its relation with the design based on ideas of perfection pursued by contemporary cities through the pretension of exercising control in all aspects of the life of the citizens. A netnography was made using the Google search engine to explore the images surrounding such searches for control and perfection of the life scenarios and of the inhabitants themselves. Finally, we reflect on the imaginaries that surround the search for a perfect society and city through the myth of Hybris.

\section{Keywords:}

Urban imaginaries; Eugenics; Nethnography.

\footnotetext{
${ }^{1}$ Doctora en Ciudad, Territorio y Sustentabilidad, Investigadora Nacional Nivel 1 de CONACYT, profesora Titular C de la UA de C. Contacto: gcarmonaochoa@yahoo.com.mx

${ }^{2}$ Doctor en Arquitectura, Investigador Nacional Nivel 3 de CONACYT, Miembro Regular de la Academia Mexicana de Ciencias, profesor Titular C de la UANL. Contacto: adolfonarvaez@gmail.com

${ }^{3}$ Ambos autores comparten en igualdad la autoría, derechos y responsabilidad del presente artículo (ambos deben considerarse para fines de crédito como primer autor).
} 


\section{Imaginarios dominantes de la purificación y el perfeccionamien- to social: la eugenesia.}

El inusitado incremento de la población que experimentaron las naciones industriales hacia el final del siglo XVIII y durante el siglo XIX, unido a la merma en la producción de alimentos para abastecer a estas poblaciones en crecimiento, llevaría a especular sobre la crisis de escasez que se avecinaba. Thomas Malthus (1798) fue uno de los primeros pensadores en advertir que las razones matemáticas de los incrementos en la productividad de alimentos y de la población eran crecientemente diferentes, pues mientras que los primeros lo hacían aritméticamente, la segunda crecía en progresión geométrica; lo que supuso, con el tiempo, nos llevaría a una crisis social irremediable por sobrepoblación y falta de alimentos. Se refirió especialmente a la necesidad de formar una ética laboral firme que llevara a la sociedad hacia una responsabilidad sobre la vida común. Advertiría que eran las clases pobres y los incapaces para trabajar los que se reproducían con mayor abundancia y que era necesario poner freno a este camino, si no se quería ir hacia el desastre:

"Aun cuando no podemos pretender excluir la riqueza y la pobreza de la sociedad, si encontráramos una forma de gobierno que permitiese disminuir el número de personas de las zonas extremas y aumentar el de la zona media, tendríamos, sin duda, la obligación de adoptarla". (Malthus, 1995: 169)

En la historia del pensamiento de occidente, estas ideas ciertamente no eran nuevas; el espíritu de la eliminación de los indeseables ha anidado en las mentes, como una herencia de la antigüedad. Platón en La República, concluye que una sociedad perfecta será aquella en la que se otorguen facilidades para la reproducción de los más aptos y se obstaculice la reproducción de los menos aptos:

"De lo convenido se desprende... la necesidad de que los mejores cohabiten con las mejores tantas veces como sea posible y los peores con las peores al contrario; $y$, si se quiere que el rebaño sea lo más excelente posible, habrá que criar la prole de los primeros, pero no la de los segundos. Todo esto ha de ocurrir sin que nadie lo sepa, excepto los gobernantes, si se desea también que el rebaño de los guardianes permanezca lo más apartado posible de toda discordia”. (Platón, 2012: 196)

Del modelo de tratamiento de los alienados sociales basado en el paradigma médico biológico se transitaría durante el siglo XIX al higienismo, una doctrina que planteaba abiertamente la necesidad de que el Estado interviniera en la vida y la salud de los ciudadanos interesándose por su cuidado. Las hipótesis de Malthus encontrarían una relación evidente con la obra del naturalista inglés Charles Darwin (1859), que proponía un mecanismo básico de adaptación para la vida y prevalencia de características en las especies, basado en la supervivencia del más apto.

Trasladadas estas ideas al plano social, no tardarían los intelectuales en hacer de las observaciones de Darwin sobre las especies animales, una metáfora de la sociedad de su época y de cómo la aptitud mayor debería de encontrarse en las capas más altas de la sociedad, mientras que las capas sociales inferiores deberían de corresponder a los caracteres menos aptos (y por lo tanto menos deseables de ser conservados como herencia). Los pensadores que darían pie al movimiento intelectual después reconocido con el nombre de darwinismo social, sobre la base de la obra de Spencer (1876), tomarían de J. Lamarck (1809) la idea de que habría ciertas características de saber adquirido que podrían ser transmitidas a través de linajes familiares por vía germinal ${ }^{4}$, con lo que, de desear conservar ciertas habilidades consideradas como superiores, habría que esperar que las familias que las poseyesen procrearan árboles genealógicos robustos. Lo que se observaría, distaría bastante de lo que sucedía en la realidad. Galton (1869), a la sazón, primo de Charles Darwin, haría notar que las características menos deseables que él mismo observaba en las clases pobres londinenses, se extendían con mayor velocidad que las de las clases superiores cuyos linajes eran menos numerosos. "Galton sugirió que, así como el hombre había obtenido extraordinarias razas de caballos y perros, se podía mejorar la raza humana controlando la reproducción" (Villela Cortés y Linares Salgado, 2011: 190).

\footnotetext{
${ }^{4}$ Una idea que en la primera mitad del siglo XX refutaría experimentalmente McDougall (1927, 1930, 1938).
} 
De estas observaciones llegaría a la conclusión de que las tendencias demográficas de su época harían con el tiempo que prevalecieran los rasgos inferiores sobre los superiores, lo que llevaría a un colapso social. Propondría entonces que era necesario que se tomaran acciones con el fin de frenar la reproducción de los linajes que tuvieran caracteres indeseables y se fomentara la reproducción de las familias con caracteres superiores. Como si hubiera tomado al pie de la letra las ideas de Platón, Galton establecía la necesidad de proteger las buenas fuentes de herencia mediante acciones directas y generalizadas. Se le atribuye haber inventado una palabra para designar su programa social: eugenesia (eugenics), que significaba literalmente buena herencia o buen nacer.

Sus ideas no tardarían en ser interpretadas como piezas clave de una política sobre la población dirigida desde el estado. A decir de Hosbawm (1987):

"la 'eugenesia'... fue fundamentalmente un movimiento político, protagonizado casi de forma exclusiva por miembros de la burguesía o de la clase media, que urgían a los gobiernos a iniciar un programa de acciones positivas o negativas para mejorar la condición genética de la especie humana." (Hobsbawm, 1987 [1998: 261])

Se planteó como el resultado inexorable de descubrimientos científicos que indicaban la necesidad de llevar a cabo acciones sobre la población, como el tributario de un conjunto de saberes científicos que los amalgamaba en un cuerpo socialmente útil (figura 1). Desde el principio se distinguió a la eugenesia positiva, que implicaba la formación de políticas de fomento reproductivo dirigidas a clases sociales e individuos que eran considerados superiores y otra negativa, que se destinaría a dificultar o eliminar cualquier reproducción humana en capas sociales o individuos indeseables. No tardaron las ideas de Galton en lograr una gran adherencia, volcándose sobre ideas inclusive más radicales:

"Eliminar al enfermizo, al deforme y al menos veloz o potente... así se impide toda degeneración de la raza por la multiplicación de sus representantes menos valiosos. Se asegura también el mantenimiento de una constitución completamente adaptada a las condiciones del entorno y por consiguiente productora de un grado máximo de felicidad." (Spencer, 1888: 353)
Figura 12. Cartel publicitario para el segundo congreso mundial de eugenesia, celebrado en Nueva York en 1921. Laughlin (1923).

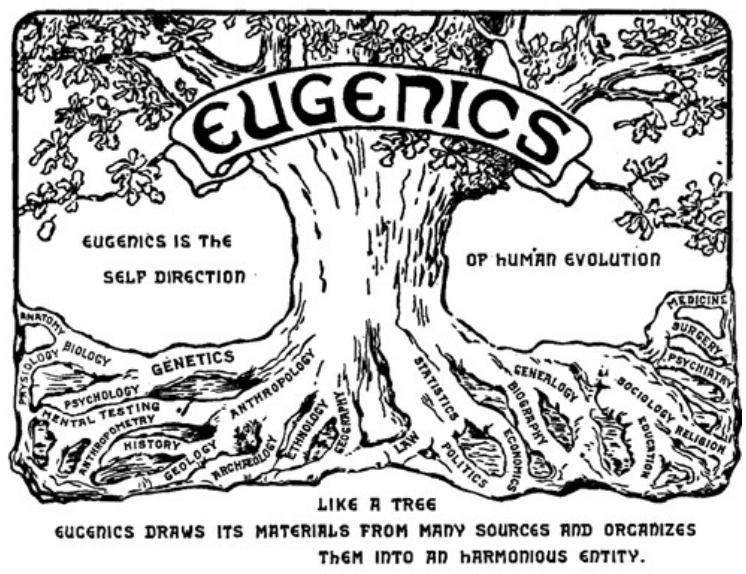

Se crearon sociedades eugenésicas primero en Inglaterra y luego en los Estados Unidos, que empezaron a presionar al sistema político para que adoptara medidas enérgicas que frenaran lo que ellos veían era una amenaza a la degeneración de la raza humana. En 1907, Indiana en los Estados Unidos fue el primer lugar en el mundo en que fueron autorizadas las esterilizaciones forzadas de personas con discapacidad, llevadas a cabo por el aparato sanitario estatal.

Le seguirían 33 estados norteamericanos en llevar a cabo prácticas similares que limitarían o eliminarían la reproducción de ciudadanos considerados indeseables, fundamentalmente personas con discapacidades de nacimiento, alcohólicos, personas racialmente no deseables (no blancas), epilépticos, enfermos mentales, etc. Para 1940 el Departamento de Salubridad de Estados Unidos inició una campaña para promover la esterilización como un método para el combate de la pobreza. De acuerdo con datos de organizaciones defensoras de los derechos humanos, hasta el año 1970 , en que se prohibieron esta clase de prácticas en Estados Unidos, se esterilizó a 65 mil personas, la mayoría de las cuales formaban parte de minorías étnicas no blancas.

En el norte de Europa las ideas eugenésicas prosperaros mucho, en 1922 el parlamento sueco aprobó la creación del Instituto Nacional de Biología de las Razas y para 1934 comenzaron las esterilizaciones forzadas. "Las leyes norteamericanas fueron miradas como un modelo a seguir por los eugenistas europeos que, azuzados por los fantasmas maltusianos surgidos tras la Primera 
Guerra Mundial, tomaron la posta de la esterilización eugénica obligatoria aprobando leyes similares" (Sánchez, 2017: 264). Fue hasta el año 1976 que fueron prohibidas esta clase de prácticas en el país escandinavo. Según cálculos de organismos humanitarios, se llegaría a esterilizar a 62 mil personas, la mayoría pacientes psiquiátricos que no dieron su consentimiento.

Otros países que aplicaron políticas eugenésicas fueron Australia, Canadá, Sudáfrica, Singapur, Noruega, Gran Bretaña, Suiza, Chile, Brasil, Argentina, Perú y México, entre otros. En Alemania durante el Nazismo (1933- 1945) las ideas eugenésicas llegarían al paroxismo del horror. Se promulgaría la Ley para la Prevención de la Progenie Defectuosa que obligaba la esterilización de personas con discapacidades físicas, mentales, o sensoriales, alcoholismo y enfermedad de Huntington. Quien inspiraría estas ideas en Alemania en esa época sería el médico estadounidense $\mathrm{H}$. Laughlin (ver figura 1) a quien, por sus servicios, la Universidad de Heidelberg le otorgaría el doctorado honoris causa.

Se calcula que las campañas eugenésicas del nazismo, conseguirían esterilizar en un lapso de sólo 4 años a 50 mil personas. Ya en plena Segunda Guerra Mundial, el programa siguió existiendo, pero con el horror desencadenado por los campos de exterminio, las acciones de los eugenistas habrían perdido visibilidad, pero quizás fue en esa oscura época cuando empezó a probarse el asesinato de los pacientes psiquiátricos diagnosticados como incurables en cámaras de gas. Se calcula que 70 mil pacientes psiquiátricos y personas con discapacidades fueron ejecutados de esta forma entre 1940 y 1941.

"Otras medidas de eugenesia negativa fueron en un inicio el infanticidio $y$, posteriormente $y$ hasta la segunda mitad del siglo $X X$, el genocidio. De forma generalizada, las medidas negativas de la eugenesia, como la esterilización y la segregación, estaban destinadas a las clases bajas, con el objetivo último de 'desaparecerlas.", (Villela Cortés y Linares Salgado, 2011: 191)

El horror descubierto en Alemania y algunos países ocupados tras la derrota del Eje fue de tal magnitud que después de la Segunda Guerra Mundial los programas eugenésicos fueron fuertemente cuestionados por la comunidad interna- cional por su filiación con el nazismo. En 1948 la Declaración Universal de los Derechos Humanos pondría fin a las prácticas negativas, no obstante que algunos países, como ya se ha apuntado antes, siguieron ejerciendo estos programas, pero ahora desde las sombras, como lo recomendaba Platón en La República.

El papel que jugaron los Estados Unidos tras el fin de la Segunda Guerra Mundial, alzándose como una de las superpotencias hegemónicas, contribuyó a extender sus ambiciones de control de la pureza de la raza más allá de sus fronteras. Las políticas eugenésicas ahora se aplicarían a otros países de los que dependería el suministro de materiales para ellos y que amenazaban con su crecimiento demográfico a la estabilidad interna de los norteamericanos.

Vemos que los programas eugenésicos realmente nunca se detuvieron. Un funcionario de vivienda de México al principio de la década de 1960, me comentó que un apoyo recibido por parte de la Alianza para el Progreso ${ }^{5}$ para la construcción de viviendas sociales, se condicionó a que una parte de ese apoyo recibido (no declarándolo públicamente, por razones obvias) se dirigiera a la esterilización de mujeres indígenas en el sur de México. De esta manera se encubría el financiamiento de un programa que atropellaba los derechos humanos de muchas personas consideradas indeseables por el gobierno de los Estados Unidos.

En una época reciente, se desclasificaron documentos del gobierno de los Estados Unidos que dan cuenta de la continuidad de las políticas de control eugenésico que ha ejercido ese país (quizás hasta el día de hoy). Resulta particularmente relevante un memorándum del Consejo Nacional de Seguridad, dirigido a la presidencia, conocido como NSSM 200 o Kissinger Report, en honor a quien fuera Secretario de Estado de aquel país en esa época.

El documento confidencial de 123 páginas, fechado en el mes de diciembre de 1974, señala como una de sus líneas principales de argumentación, que había ciertos países clave para la estabilidad política, social y económica de los Estados Unidos, ya que representaban fuentes de suministros de materiales esenciales para su desarrollo industrial, sobre los que se deberían de enfocar esfuerzos para el control del crecimiento de sus poblaciones. Los países que se identifican como

\footnotetext{
${ }^{5}$ Un programa de "ayuda” a los países en subdesarrollo que se dio durante la administración del presidente norteamericano John F. Kennedy.
} 
tales en el memorándum son: India, Bangladesh, Pakistán, Nigeria, México, Indonesia, Brasil, Filipinas, Tailandia, Egipto, Turquía, Etiopía y Colombia. En el documento se argumentaba que esas naciones eran las que representaban el $47 \%$ del incremento mundial de la población en ese momento, por lo que, de no controlarse a esas poblaciones, era fácil que se volvieran políticamente inestables y adversas a los intereses de Estados Unidos, con lo que se podrían romper las cadenas de suministros para aquel país.

Lo que plantea el reporte es que se promueva en estos países una reducción de sus poblaciones por la vía de la esterilización, la anticoncepción y el aborto principalmente y otras medidas de limitación y contención. Viendo este documento panorámicamente, es fácil observar que ahí la eugenesia es planteada como la eliminación sistemática y soterrada de las poblaciones indeseables para ellos; en el fondo, ya lejos de sólo considerar a las personas enfermas, viciosas o con discapacidad como los únicos que eran un problema para la prosperidad del Estado, ahora se consideraban como problema a naciones enteras, basándose en su etnia y en su cultura. Eso, enmascarado en un discurso de pragmatismo económico, es en realidad puro racismo.

Es muy posible que estas políticas de limitación del crecimiento de nuestra población por la vía de la esterilización química a través de alimentos, vacunas o fármacos distribuidos por medio de los organismos nacionales de salud, siga siendo llevada a cabo actualmente. Esta clase de eugenesia, aún con la negra historia que le rodea, sigue siendo una política de Estado, sin lugar a dudas, a través de la que se diezma a poblaciones consideradas como no esenciales o inclusive indeseables.

No se puede descartar que, además, se pudiera ejercer control sobre los objetivos, contenidos y métodos de la educación que se dirige a ciertas poblaciones en las que se desea fomentar la producción de buenos y fuertes intelectuales (eugenesia positiva), mientras que a otras poblaciones se les limitaría el acceso a una educación de buena calidad, con tal de sostener su dependencia y limitar el surgimiento de pensadores potentes y críticos entre ellos; ni tampoco se puede descartar que se limiten otros campos de acceso a bienes, tecnologías o conocimientos de mayor calidad (salud, vivienda, producción de alimentos, informática, comunicaciones, etc.) mediante políticas de Estado dirigidas desde organismos de financia- miento para el desarrollo, como el que describo antes, promovido por el gobierno de Kennedy; que pude conocer de primera mano.

A toda esta corriente que se desarrolló a lo largo del siglo XIX y XX se le conoce como Eugenesia de Estado debido a que se deja en manos de los gobiernos la implantación obligatoria de medidas de control eugenésico, limitándose o a veces pasando por encima de los derechos individuales.

La eugenesia misma ha cambiado con el tiempo. El descrédito que acarreó esta corriente al campo de las políticas sociales apoyadas casi exclusivamente desde la visión médico-biológica, ha llevado a adoptar otros paradigmas de pensamiento y acción en el trato que se brinda a las personas con discapacidad. Padilla Muñoz (2010) señala que hubo un cambio en la concepción de la persona desde ser considerada como "enferma del cuerpo" a ser el producto de una serie de contingencias sociales limitantes, lo que daría lugar al planteamiento de un modelo de tratamiento que ella identifica como de "discapacidad social" que "postula que la discapacidad no es solamente lo derivado de la enfermedad de la persona, sino el resultado de condiciones, estructuras, actividades y relaciones interpersonales insertas en un medio ambiente que en mucho es creado por el hombre" (Padilla Muñoz, 2010: 404).

La eugenesia de Estado prácticamente ha sido proscrita como filosofía para la creación de políticas públicas, no obstante, en el ámbito privado, las ideas eugenésicas han proliferado bastante, sobre todo a partir de la investigación sobre el genoma humano.

Ello ha dado pie a lo que se conoce actualmente como "eugenesia liberal":

"Caracterizada por tres aspectos diferenciales respecto de la eugenesia de Estado: 1) ser voluntaria, lo cual implica que la decisión de modificar la carga genética de los hijos por nacer se efectúe sin coerción; 2) individual, esto es, realizada por núcleos familiares y únicamente con la finalidad de modificar su progenie, y no para alterar acervos genéticos de comunidades completas, y 3) independiente del Estado, para que este no promueva ningún aspecto genético, evitando así la creación de moldes." (Villela Cortés y Linares Salgado, 2011: 195)

En la actualidad, esta visión consiste fundamentalmente en aplicar el conocimiento sobre biología molecular que se ha derivado de la completa decodificación del genoma humano para 
realizar diagnósticos e intervenciones genéticas que buscan cambiar nuestro genotipo con miras a modificar nuestro fenotipo, de manera que consigamos alterar artificialmente el rumbo de nuestra evolución biológica, escogiendo sólo aquellas características que harán que nuestra descendencia se vuelva fuerte, saludable y virtuosa; tanto física como intelectualmente. El problema que entraña esta visión obviamente radica en definir cuáles características serían mejores que otras y las razones para eliminar unas características en la herencia, amén de que ello implicaría un "adelgazamiento" de la natural diversidad de rasgos heredables de nuestro acervo genético como especie.

Pero esas razones no pueden explicar completamente la fuerza de esa búsqueda de lo perfecto en nuestra cultura, que nos lleva a tales extremos de exterminio de lo indeseable y deseos de transformación por vías que pueden llegar a ser brutales (aunque sea sólo a través de nuestra febril imaginación de futuro). Pero que al mismo tiempo animan a la construcción de la arquitectura y las ciudades en las que vivimos.

En el centro de toda esta cuestión parece hallarse una compulsión por el control. Que escala más allá de toda racionalidad hasta niveles que tienen que ver con el control absoluto. Una compulsión que es a la vez megalómana y que se afinca en certezas hondamente enraizadas, que estarían ligadas a poderosas imágenes de nuestra cultura.

Se trata de imágenes de perfección que tienen tal poder, que parecen borrar toda sombra de duda de que se pueda lograr el llegar a una perfección así y que borran toda capacidad crítica que pudiese cuestionar los medios que tengan que usarse para llegar a ese estado.

\section{La casa y la ciudad perfectas.}

Hay un afán de perfeccionar al hombre y a la naturaleza que subyacen al pensamiento y a las acciones de los eugenistas. Las pretensiones (desmesuradas) intentan crear un hombre nuevo, algo que es una idea, una imagen y mucha fuerza emotiva encerrada en uno de los grandes mitos que fundan al imaginario en occidente. El hombre nuevo que surgiría de las cenizas del imperfecto hombre del pasado, sería el adalid que vendría a reverdecer el campo marchito dejado por su imperfecto predesesor.
Son abundantes los mitos que se refieren al ascenso del héroe y ya se ha discutido en otros trabajos de qué maneras se relacionan estas imágenes, símbolos, narraciones y preceptos, con las pulsiones de poder - de un poder sin límites, omnímodo y voráz- que quisiera abarcarlo todo, que es al mismo tiempo colonizador de los territorios y de las conciencias (Narváez, 2012).

El poder que se dirige al cuerpo, que se encauza a hacer del cuerpo el campo de su expresión y el vehículo por el que sus preceptos son aprendidos, es el mismo que se dirige posteriormente al lugar en el que ha de habitar el hombre, especialmente a su casa y a la ciudad. Es así que como manifestación paralela del proyecto de "limpieza" que se ha planteado como núcleo de las ideologías que se han expuesto antes, ha habido la intención de crear un escenario perfecto para que tenga lugar la vida de una humanidad "purificada".

La perfección de la casa y la ciudad que han perseguido los poderes dominantes, se ha dirigido hacia un proyecto centrado en la vigilancia, en la seguridad y en la salud. El emblema principal de estas ideas quizás lo representen las transformaciones de París emprendidas por encargo de Napoleón III, al Barón Haussmann a mediados del siglo XIX.

El proyecto de Haussmann consistió en reestructurar el viejo París medieval de estrechas y serpenteantes calles, principalmente a través del trazado de amplios bulevares, canalizaciones, obras para la movilidad y la construcción de edificios púbicos que sirvieron en parte para el embellecimiento de la ciudad y en parte para la ubicación de fuerzas públicas para aplastar cualquier rebelión popular.

Los bulevares son quizás la parte más visible del plan de Haussmann y también lo que mejor refleja a los objetivos de conseguir una ciudad perfecta: amplios, luminosos, ordenados, ventilados. Afincándose en la idea de conseguir entornos más higiénicos, que sanearan la atmósfera aplastante, húmeda y pestilente de la ciudad predecesora, ofrecían una imagen que explícitamente representaba el progreso. Un progreso basado en un orden predecible a través de ordenanzas que preveían alturas y alineamientos similares de los edificios que bordeaban los bulevares, eliminando con ello la variedad, haciendo así una ciudad más "legible", en el sentido de hacer inteligible el conjunto urbano, evidentemente 
obra de la acumulación de acciones desvinculadas, para hacerlas un solo proyecto, que reflejase una sola voluntad (la del poder). Evidentemente, se trataba de un proyecto que era fabricado para una mente racional.

Lo que se consiguió con este proyecto, de acuerdo con la mayoría de los críticos, fue además una sectorización efectiva de París, para de este modo hacer posible controlarlo mediante la fuerza pública, previniendo con ello revueltas populares como las que habrían tenido lugar unos años antes de que se emprendieran las obras de reforma urbana. Además, los historiadores coinciden en que el proyecto en sí tuvo como fines (ocultos) abrir a la vieja ciudad a un nuevo mercado inmobiliario que terminó atrayendo al centro a las clases sociales más acomodadas y desplazando a las clases trabajadoras a las periferias.

La luz, el orden, la claridad esquemática del proyecto de Haussmann puede intuirse como herencia de toda una tradición del pensamiento urbanístico europeo gestado desde el renacimiento. En efecto, en el proyecto de la ciudad ideal es posible ver los primeros atisbos de lo que pudo conseguirse a la escala de los grandes proyectos urbanos del siglo XIX (ver figuras 2a y b).

Figura 2a. Ciudad de Palmanova, Italia, siglo XVI, atribuida a Vincenzo Scamozzi. Morris (1984).

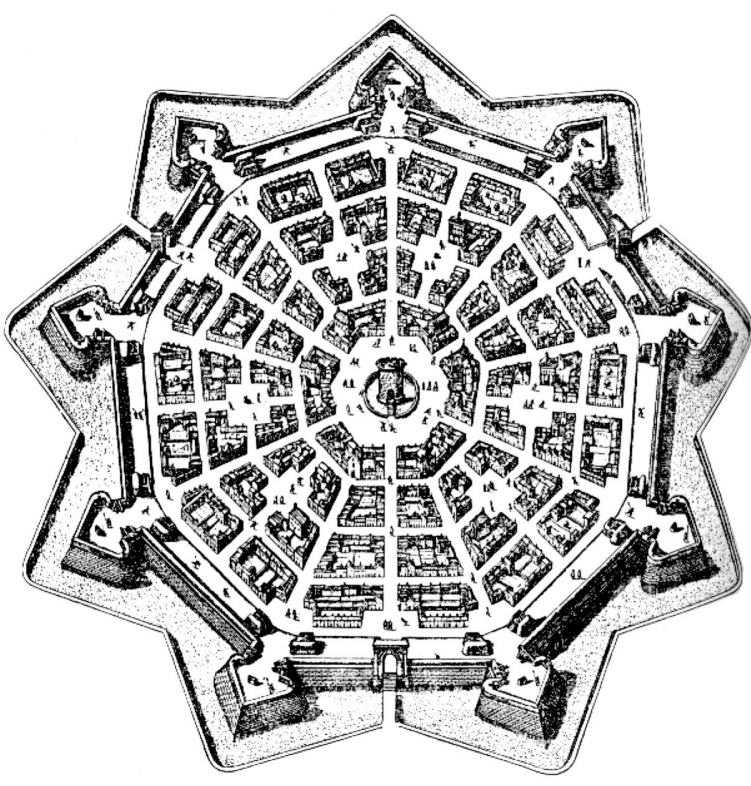

Figura 2b. Trazado viario alrededor del Arco del Triunfo, París. Google maps, 2018.

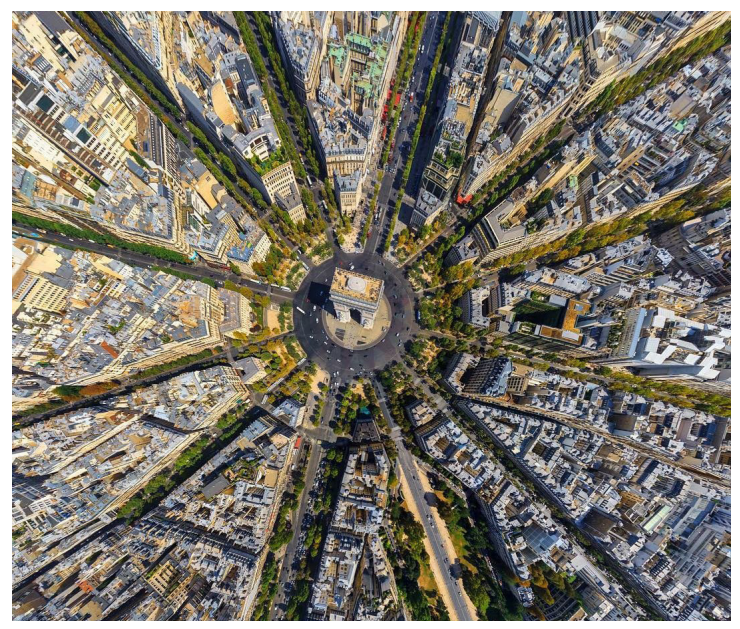

Se gesta a partir del renacimiento europeo una manera nueva de ver al mundo. Ya en la obra de Bacon (1628), que hace referencia implícita a La República, se advierte que la naturaleza tiene que ser doblegada por la razón, lo que establece un método de trabajo que abandona el cambio de las estructuras sociales a través de la política y de la imposición de una nueva ética, para dirigirse al dominio mediante el uso de la ciencia y la tecnología.

El renacimiento sentaría las bases para el dominio de la razón como medida para el progreso. Las imágenes que están ligadas a este dominio tienen que ver con la limpieza, con la luz. En la equiparación de la luz con la razón, hay una analogía con lo espiritual. Su oposición, las tinieblas, estarían ligadas a lo corpóreo y de ahí a lo sensual. Hay en el proyecto renacentista un desapego de lo material que hace necesaria la limpieza de todo rastro de materialidad.

En esa limpieza se eliminarán los atributos cercanos, lo táctil, lo olfativo, para dar preeminencia a lo visual y lo auditivo, que así puestos se transformarán en opuestos, donde por su equiparación, se ligarán a un orden moral que tiende a apartarnos de lo corporal (la materia) para llevarnos al espíritu (la luz).

La equiparación de las tinieblas con lo monstruoso, con lo deforme, establecerá las bases para definir a un orden perfecto libre de toda mácula, que desplazará (hasta desaparecer) a la anomalía.

Los nuevos diseños de las ciudades y de las casas respondían a un ideal de salud perfecta, siendo, como es ahora evidente, poco realistas. 
Para deshacerse de esta falta de contacto con la realidad en la que existía la enfermedad, la discapacidad y la vejez, se crearon instituciones civiles para corregir y para encerrar a los anormales de toda índole. En el afán de lograr comunidades que reflejaran a la perfección, se llegarían a formular visiones de embellecimiento urbano y de reformas sociales ( entre los que cabría señalar al movimiento City Beautiful, los proyectos de ciudad jardín, el socialismo utópico, etc.) que en sí planteaban elementos de una visión poderosa: conseguir un mundo nuevo, dirigirse hacia un mundo sin defectos, que apartara a todo lo indeseable.

Un mundo sin enfermedad, sin pobreza, sin contaminación, inmaculado, que heredamos del higienismo y de otros movimientos urbanísticos del siglo XIX, es el que será la fachada más visible de la arquitectura del movimiento moderno en la primera mitad del siglo XX, para dejar tras de sí un proyecto de crecimiento económico, de productividad y de eficiencia. La ciudad y la arquitectura del movimiento moderno, realmente es la expresión más brutal del sistema económico capitalista. En efecto, el ideal de este movimiento enmascara la necesidad de contar con todos los miembros útiles de la sociedad para el trabajo. La ciudad moderna es así indisociable del mundo laboral.

No es posible pensar en la ciudad moderna sin plantearse que está afincada en el trabajo, por lo que la enfermedad, la discapacidad, la vejez, serán enemigos de ese proyecto. Los instrumentos para proyectar la casa, desde esta perspectiva que busca la eficiencia y la maximización de los rendimientos del trabajo, serán aquellos que limiten el costo y el esfuerzo para construir, para usar o para mantener.

En la obra de la arquitectura moderna, sobre todo en aquella dirigida a la construcción de la vivienda, el imperativo es la reducción, la eficiencia y el empleo racional de los materiales, lo cual puede quedar garantizado mediante la modulación, según lo descubrió Durand a finales del siglo XVIII. Actualmente, la unidad de medida usada para proyectar la casa es el hombre. Los principales teóricos y prácticos del movimiento moderno establecerían la base de ello en un hombre idealizado, para desde sus medidas deducir las de su morada.

Este no es un asunto nuevo en absoluto. Desde la descripción del hombre perfecto del romano Vitruvio en su tratado, escrito hace más de 2000 años, ha habido esfuerzos por hacer encajar a las medidas del hombre en esquemas geométricos y matemáticos que expliquen la armonía de sus proporciones. Con bastante éxito se ha demostrado desde la antigüedad que la proporción áurea puede servir como modelo geométrico para la definición de las medidas humanas de un hombre idealizado, por lo los arquitectos suponen que este patrón, al ser usado para el proyecto de arquitectura, ayudará a hacer compatibles a las medidas de la obra con las de los seres humanos.

El célebre dibujo del hombre de Vitruvio hecho por Leonardo, ilustra muy bien estos principios de la investigación sobre geometría antropocéntrica. Le Corbusier (1953), tomaría estos principios para la producción de un sistema de medidas que abandonara los sistemas métrico (geocéntrico) e inglés, de cara a lograr una mejor adaptación del diseño arquitectónico, mecánico y de objetos a las medidas humanas y a la necesidad de estandarizar los elementos industrializados de la construcción.

Consigue a partir de su investigación sobre la geometría áurea, crear una rejilla de medidas para la estandarización de los elementos de construcción. La base de su medida humana primero fue su propia estatura (1.75 metros), que se adaptaba muy bien a la media de los franceses (Le Corbusier, 1953: 41).

De esta investigación, deduce las medidas básicas de un enrejado útil para la modulación del proyecto, ajustando las medidas de las posturas humanas con la geometría áurea, dentro de una progresión de Fibonacci, con lo que considera, una perfecta adaptación del edificio a las personas. Le Corbusier posteriormente bautizaría a este enrejado como Modulor 1 (figura 3).

Figura 3. Modulor, Le Corbusier. Portada de la edición francesa de $\mathbf{1 9 5 0 .}$

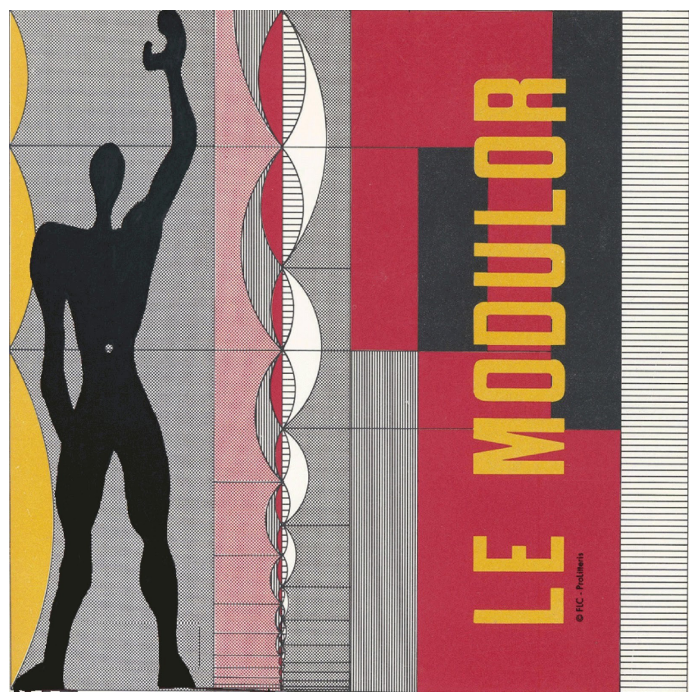


$\mathrm{Su}$ viaje a los Estados Unidos y su encuentro con industriales de aquel país, le hicieron replantear la estatura del hombre perfecto que había considerado para el Modulor 1 y que para el caso de la media estadounidense de la postguerra resultaba algo corta. El 1.80 metros de la media de estatura estadounidense fue "redondeado" a 1.83 (6 pies), con lo que ya conseguía una mayor compatibilidad con el sistema inglés y con una posible aplicación industrial de su invento (Le Corbusier, 1953: 59).

A esta segunda versión le bautizó como Modulor 2 y a la postre, sería la versión que él aceptaría universalmente para el proyecto de sus obras. Pese a que los sistemas Modulor no resultaron aplicados comercial e industrialmente en la medida que Le Corbusier había soñado, el modelo de investigación sirvió para alentar la adaptación de las medidas de los elementos y materiales de la construcción a unas medidas humanas estandarizadas y a la creación de ciertos módulos útiles.

La investigación en antropometría y ergonomía, ha demostrado cambios en las medidas humanas de las diversas poblaciones del mundo a lo largo del tiempo, con lo que la idea de la universalización de las medidas humanas para lograr el diseño perfecto, que pretendieron Le Corbusier y sus seguidores, resulta inaplicable y hasta ingenua.

El tiempo nos ha mostrado, cuando visitamos algunas de las obras maestras de la arquitectura moderna, que éstas han experimentado un paulatino desajuste de sus medidas con respecto a las del ser humano actual.

Lo que además es necesario ver de este proceso, es cómo se llegó a estas ideas. Se parte de la idealización del hombre y de ahí se deduce la arquitectura, esta forma de abordar el problema contiene fallas enormes, pues hay grandes variaciones entre las poblaciones y entre los individuos, sus medidas y sus condiciones de movilidad.

Sin embargo, el proyecto actual de vivienda sigue tercamente unido a esta filosofía industrial profundamente equivocada. Basar el proyecto en la modularidad de los diseños y en la repetición, que consiguió grandes rendimientos para los industriales, ahora ha quedado atrás. En muchas áreas de la fabricación de objetos, ya no se concibe la producción en serie, por ejemplo; ésta ha sido sustituida por la producción a la medida, con lo que se consigue la fabricación de objetos únicos, pero por medios industriales.

Esta nueva filosofía de fabricación, al mismo tiempo que ajusta perfectamente el objeto al usuario, ahorra materiales.

Basamos el diseño de la casa y la ciudad perfectas justamente en esa idealización, que, como ha sido demostrado en este trabajo, resulta de una manera de imaginar al mundo que discrimina, que quiere limpiar la anomalía, que pretende eliminar lo imperfecto, que es realmente aquello que no se ajusta a esa visión idealizada del hombre. En el camino de hacer esta ciudad perfecta se cometen injusticias que no pueden seguir tolerándose, que hacen de esas "ciudades perfectas", objetos que en ciertas condiciones pueden resultar inclusive inútiles. ¿Qué subyace a estas imágenes de cristalina perfección?

\section{La perfección y la ciudad en el imaginario contemporáneo: euge- nesia y ciudad en internet.}

Realizamos un estudio netnográfico (Carmona, 2015) a partir de la búsqueda de imágenes en Google de las palabras clave "eugenesia-ciudadano" y para ampliar la búsqueda se introdujeron términos en inglés "eugenics-city"; se analizaron las primeras imágenes que arrojó el buscador para cada grupo de términos. Hay una jerarquía ordinal en las imágenes provista por la popularidad de consulta del ítem basada en el algoritmo de búsqueda de Google (Cassin, 2008), se procedió a realizar el estudio de los mensajes visuales tal y como se posicionan por el algoritmo. La jerarquía observada puede ser isomorfa con la red semántica natural.

El análisis posterior de las imágenes fue tomado del método sobre el lenguaje visual de María Acaso (2009). Lo primordial en este método es distinguir entre el mensaje que transmite una imagen a los dos primeros segundos de ser observada y el mensaje profundo de la misma al hacer un estudio más detallado, ya que "con este tipo de mirada superficial son las imágenes las que ejercen su poder sobre nosotros, logrando que desarrollemos comportamientos específicos" (Acaso, 2009: 143). 
Figura 4. Primera captura de pantalla "eugenesia-ciudadano".

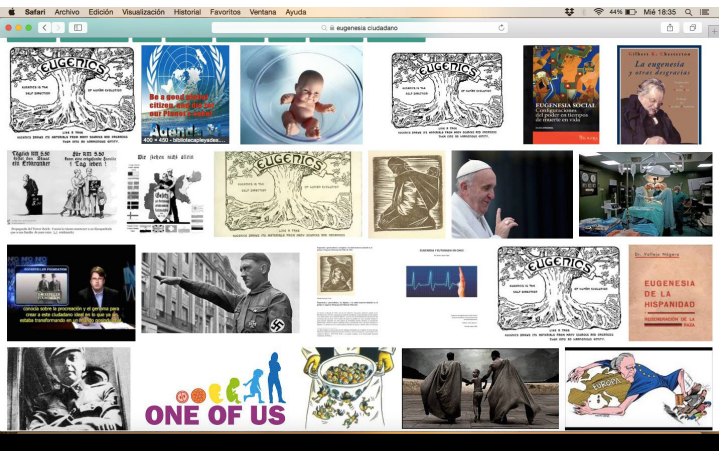

Fuente: Google images, 1-08-2018.

Figura 5. Segunda captura de pantalla "eugenics-city".

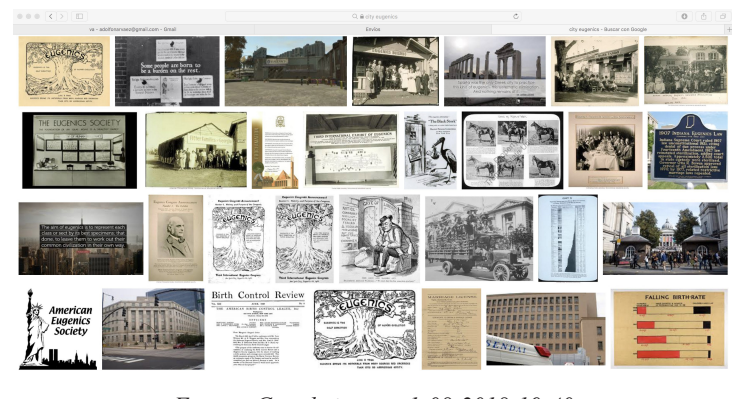

Fuente: Google images 1-08-2018-19:40.

En una imagen grafica se distinguen dos tipos de mensajes: el mensaje manifiesto y el mensaje latente. El método de Acaso (2009) se divide en cuatro fases: clasificación del producto, estudio del contenido, estudio del contexto y enunciación de los mensajes manifiesto y latente.

En total son veintitrés las primeras imágenes que se pueden observar en la pantalla al teclear las palabras clave "eugenesia-ciudadano" (figura 4). Del total, siete son el blanco y negro, cuatro en color sepia y doce sí tienen colores, aunque la búsqueda se realizó en español hay cuatro imágenes en donde se puede observar claramente la palabra en ingles escrita en mayúsculas: eugenics, palabra colocada sobre las ramas de un árbol con fuertes raíces (la misma de la figura 1); se observan en seis imágenes diferentes la figura de bebés, el bebé que se vé con más claridad evidentemente es de plástico; en cinco imágenes aparecen la cantidad de veintitrés niños pequeños, en catorce imágenes vemos veinticinco adultos, en dos imágenes parecen dos personas adultas de raza indígena; en una imagen claramente aparece Adolfo Hitler y otra con una persona del ejercito nazi, sólo se observa una persona discapacitada, en una imagen aparece Su santidad el papá Francisco; vemos también sólo dos adultos mayores y doce adultos jóvenes, cuatro médicos; en total se observan treinta personas de raza blanca. Hay tres portadas de libros sobre el tema de eugenesia, una imagen proveniente de un video en YouTube. El buscador Google relaciona la búsqueda con las siguientes palabras: nicht allein, eugenesia social, elite, eutanasia, Rockefeller, control propaganda, Francis Galton.

De las veintitrés imágenes que se pueden ver en la figura 4, doce son dibujos, siete son fotografías, los colores que predominan en las doce imágenes a color son el azul, gris y un poco de rojo. Las palabras que se observan claramente en el conjunto de imágenes son: principalmente eugenics, eugenesia, hispanidad, Europa, one of us, agenda 21.

A simple vista se notan: espacios en blanco, palabras en español y en ingles, aunque también hay en alemán, pero son poco notorias, la foto de Hitler es muy evidente al igual que la imagen del papa Francisco, el bien y el mal, en una sola página, se observa tristeza y enojo, es una composición de imágenes grises y sin vida. Una discusión grafica entre lo que está bien y lo que está mal. Es notoria en esta imagen la aparición de muchas referencias en el idioma ingles, por lo cual nos llevó a realizar una segunda búsqueda en este idioma buscando la relación entre la ciudad y la eugenesia; utilizamos como palabras clave para esta nueva búsqueda "engenics-city" (eugenesia-ciudad).

En total son 30 imágenes las correspondientes a la segunda captura de pantalla "engenics-city" (figura 5). Claramente observamos que el color general de las imágenes que aparecen es en gris y en sepia, vuelve a aparecer en cuatro ocasiones eugenics palabra colocada sobre las ramas de un árbol; en siete de las imágenes observamos personas, seis de ellas son imágenes antiguas y una es actual, también vemos que de las imágenes antiguas cuatro son fotografías realizadas a un grupo de personas que están reunidas por algún motivo en especial. Nueve del total de las treinta imágenes son dibujos el resto son fotografías, en dos aparecen animales, una cigüeña y caballos; en una imagen aparece claramente un grafico de la estatua de la libertad y de fondo el contorno de la Ciudad de Nueva York pues observamos el perfil de las desaparecidas Torres Gemelas, el Empire State y el Met Life Building de Chrysler, hay doce imágenes en la cuales vemos claramente 
reflejada la segunda palabra clave que es ciudad, vemos una imagen que tiene unas ruinas griegas, una hace referencia a una gran metrópoli que al igual que la imagen de la estatua de la libertad nos remite a la Ciudad de Nueva York, en dos imágenes más, se fotografían edificios de arquitectura funcionalista, fachadas planas, sin ningún adorno, ventanas en serie, colores neutros; en otra de las imágenes se observa arquitectura neoclásica. En el resto, la ciudad está de fondo no es el objetivo de la fotografía o del gráfico la ciudad. Por último, vemos una serie de gráficas e imágenes de noticias, pero ambas remiten al pasado. En resumen, este conjunto de imágenes por sus colores, las personas que se observan, la arquitectura, el diseño gráfico, la tipografía, nos remite al pasado. El buscador relacionó nuestra búsqueda con las siguientes palabras clave: control natal, inmigración, esterilización, propaganda, años 30.

En cuanto al contexto, es decir, quién las hizo y para qué se crearon las imágenes, se señala que en el caso de la figura 4, por lo general provienen de sitios web y sirven para complementar una definición, un ensayo, una noticia, un artículo científico, noticias de difusión de teorías conspirativas y en ciertos casos ilustran activismo político llevado a cabo en la red.

En el caso de la figura 5, en cuanto al contexto las imágenes provienen de sitios web y sirven para complementar de manera grafica páginas de activismo pro-vida, ensayos científicos o artículos periodísticos. Encontramos también la reseña de un video juego, la historia del término, la historia de un psiquiátrico en NY, activismo anti-evolucionista y antisemita, historia de las adopciones, activismo anti-eugenesia, también encontramos activismo pro-eugenesia de un laboratorio de genética actual, artículos de organizacióones pro-eugenesia liberal, pero a la par se encontró una denuncia a la organización eugenista de Estados Unidos la que señalan cercana en sus ideas a las del nazismo.

Es posible determinar con los elementos anteriores el mensaje manifiesto y el mensaje latente de la imagen en general. El mensaje total que nos da el conjunto de imágenes que aparecen en la figura 4 es un mensaje de un tema serio, los colores que predominan son tristes, no hay caras sonrientes por lo contrario hay enojo. Los personajes que evidentemente se pueden observar (Hitler y el papa Francisco) son antagónicos, lo que nos refleja que por una parte en el tema hay maldad y por otra hay bien, al aparecer en varias ocasiones el logo del congreso de 1921 impulsado por Laughlin, nos damos cuenta de la importancia del mismo, es decir es una referencia necesaria en el tema, se observa lo triste del tema, el enojo que causa, lo falso, lo gris del propósito, hay niños pero no se aprecia alegría. A simple vista se notan espacios en blanco, palabras en español y en ingles, aunque también hay en alemán, pero son poco notorias, la foto de Hitler es muy tan evidente al igual que la imagen del papa Francisco (el bien y el mal), se observa tristeza y enojo, es una composición de imágenes grises y sin vida. Una discusión grafica entre lo que esta bien y lo que está mal.

Por otra parte el mensaje total que nos envía la figura 5 es referente al pasado, por los colores y el entorno en general, aunque sabemos cuando se realizó un búsqueda mas profunda en cada sitio web que al igual que en las imágenes de la figura 4 existe una discusión en pro y en contra del tema, en esta imagen no es evidente, en cambio sí es evidente el pasado, la seriedad, las grandes ciudades como contexto, como referencia al término, y en especial Nueva York que se le ha considerado como una de las ciudades globales y todo lo que esto representa, diversidad, riqueza, cosmopolita, triunfo, donde suceden las cosas, pero no en este caso; la ciudad representa otra cosa, representa las ciudades clásicas, las ciudades funcionalistas, las ciudades perfectas, hay una resonancia de pasado en ello de una perfección buscada, encontramos que el tema está políticamente vivo en la actualidad.

¿A qué imaginarios nos remiten estas representaciones que implican la búsqueda de una humanidad perfecta? ¿Qué significados ha atraído en la historia esta búsqueda, cuáles son sus raíces en nuestro imaginario? ¿Qué implican profundamente las imágenes de perfección?

\section{Conclusiones. Imaginarios de per- fección y pulsión de poder.}

Una imagen perfecta es uno de los medios a través de los cuales tenemos la esperanza de conseguir algun control sobre la realidad. Una imagen perfecta se forma por la necesidad de conseguir seguridad y certeza, frente a un mundo que se presenta al ser como algo ajeno y amenazante.

Las imágenes de perfección, al ser las depositarias del deseo de que se alcance un estado que se intuye será el que se ajuste exactamente con 
unas condiciones preestablecidas, generalmente es el origen de impaciencia, frustración, ira y resentimiento, que puede tener manifestaciones en la vida social. El origen de las imágenes de perfección del mundo como las que se han expuesto en este capítulo, normalmente es externo y ajeno a la persona, pero es algo que se experimenta en forma personal, las imágenes de perfección nos implican profundamente.

Las imágenes perfectas surgen de modelos condicionados socialmente que sirven para dar soporte a posiciones éticas que establecen formas de relación con los otros. Los modelos que engendran a las imágenes perfectas son por definición inalcanzables (Valera, 2018). Esa inalcanzabilidad esencial es quizás la que lleva a la persona hacia esa espiral descendente de frustración, ira y tristeza que va mermando su poder para hacer y decidir. En el fondo, los modelos de los que surgen las imágenes de perfección, son como instrumentos que atrapan a la persona, medran y viven de su energía personal, haciéndola luego esclava de sus promesas luminosas: se trata de eficaces instrumentos del poder.

Los modelos a su vez se apoyan en grandes imágenes míticas. La búsqueda de la perfección establece la posibilidad de crear un mundo que se asemeje al paraíso. En efecto, esa poderosa imagen parece guiar y dar fuerza a la esperanza que anima la construcción de un mundo que esté "limpio" de todas las imperfecciones. La búsqueda del paraíso perdido encierra en sí misma la desazón y el vacío de una vida luminosa que ya no se tiene. Imágenes como la bíblica Torre de Babel y su pretención de crecer hasta alcanzar la altura de Dios, pueden ilustrar a la esperanza de hacer el cielo en la tierra, de volver a ese paraíso del que se nos ha expulsado.

La mítica Torre, la historia de Prometeo, el titán que regaló el fuego a los hombres, el prodigioso invento de Dédalo, que llevó a Ícaro a remontar los cielos, todas estas poderosas imágenes tienen en común la caída, la ruina, y en ésta, la frustración que es engendrada por una inalcanzabilidad escencial. Pero la caída es llevada fuera del hecho mismo de buscar una empresa imposible, encarnándola en la tiranía de unos dioses que destruyen las pretenciones que ellos mismos califican como desmesuradas.

Para los griegos de la antigüedad se trataría de hybris, un principio, una fuerza, hija de los dioses primordiales Érebo (la insondable oscuridad que rodea al mundo) y Nyx (la noche), que empuja- ría al hombre a la desmesura. El castigo por tal comportamiento, acontecía siempre como una trágica vuelta a la mesura que era expresada a través de terribles imágenes de castigos eternos y tan desmesurados como el crimen de exceso que los había motivado.

Hybris puede entenderse también como una enfermedad (Owen, 2010), que conduce a la persona desde una autoimagen exacerbada e infalible, hasta comportamientos tiránicos en donde se tratará de eliminar todo lo que contradiga a la opinión propia (eliminando o minimizando las ideas y declaraciones de los otros y a veces, como en el caso de prominentes personajes políticos, eliminando a los mismos disidentes). Por debajo de esa superficie de suficiencia y perfección imaginada, parece haber sentimientos de insuficiencia y de carencia; debajo de la apariencia de poder y dominio, existe en quien padece esta patología una autoestima muy baja que se relaciona, además, con ansiedad por la amenaza del medio que le rodea, lo que puede conducir al desarrollo de delirios de persecución.

La desmesura es castigada en los mitos a través de imágenes de caída y pérdida. Quienes han osado intentar acercarse a los dioses son llevados así a su castigo. Hay una evolución que se percibe en el pensamiento de occidente que va desde la primitiva noción de castigo divino hasta la noción de pecado. La desmesura o soberbia es así planteada por el imaginario occidental cristiano precisamente como uno de los posibles orígenes del pecado:

"Algunos dicen que la soberbia se toma en tres sentidos. Primero, en cuanto que soberbia significa el deseo desordenado de la propia excelencia. Y así es un pecado especial. En segundo lugar, en cuanto implica cierto desprecio actual de Dios respecto al efecto de no someterse a sus preceptos. Y así dicen que es un pecado genérico. Tercero, en cuanto implica cierta inclinación a semejante desprecio, debida a la corrupción de la naturaleza. Y en este sentido dicen que es el principio de todo pecado" (De Aquino, Tomás Santo, 1993: 652 c 84 a 2).

Se intuye que para la visión cristiana y de la antigüedad, existió una limitación a mostrar ideas, deseos o comportamientos desmesurados, que serían asociados ya en el imaginario cristiano con la ofensa a Dios y con la desobediencia.

La soberbia es vista como origen del mal y también como la que engendra al mal, situán- 
dose en el centro y aparte de las demás: "La soberbia, como vicio universal, no se enumera con los otros, sino que más bien se la pone como una especie de reina de todos los vicios" (De Aquino, Tomás Santo, 1993: 656 c 84 a 4). La imagen del principado de este pecado, cometido según la tradición por el primer apóstata, Lucifer, sitúa a la desobediencia, que en su origen tiene la desmesira de pretender ser más que Dios, por encima de todos los demás; si se quiere ver esto como una representación militar, se encontraría en su comando.

Esa jerarquía pecaminosa ya establece una estructura útil para el análisis, pues indica por la vía negativa la importancia dada a la desmesura, pero también su cura: "Las riquezas se renuncian por el voto de pobreza; los deleites de la carne, por la perpetua castidad, y la soberbia de la vida, por la sujeción a la obediencia" (De Aquino, Tomás Santo, 1993: 898, c 108 a 4). La obediencia, así sería el comportamiento que conduce a la luz de Dios. Diferentes mitos y costumbres en occidente ponen de relieve la importancia de la mesura como norma de comportamiento, con lo que subrepticiamente se establecen las bases de una ética encaminada al control y al sostenimiento del poder.

Trasladada la imagen del dios a la del soberano, es en esta medida crucial garantizar la sujeción a su mandato y la mansedumbre de todos sus actos y pensamientos. "Ofrecemos el becerro cuando vencemos la soberbia de la carne" (De Aquino, Tomás Santo, 1993: 822, c 102 a 3) ${ }^{6}$. El becerro de oro es ofrecido en sacrificio, cuando se ha vencido a la idolatría, es decir, cuando se deja de poner en la materia tosca mayor valor que en lo espiritual. Esta imagen es muy poderosa como indicadora de una ética recta para el pensamiento judeocristiano: la gran decepción de Moisés a la vista de un pueblo que volvía a sus prácticas idólatras, que era tan duro de corazón como para no ver los milagros que el Dios verdadero, había obrado en ellos para su salvación y que les ofrecía Su ley en manos del profeta, es la imagen de una regresión, de una involución.

En efecto, esta imagen, que en sí exhibe a la desobediencia y a la búsqueda de lo material por encima de lo espiritual, mantiene una de las formas más fuertes del imaginario en occidente, situando en el ámbito del bien al espíritu y a la materia en el ámbito del pecado. La escena bíblica establece una geografía y una topología para esta indicación moral, situando en lo alto de un monte al espíritu y en el fondo de la cañada a lo material. Arriba y abajo se asientan así como antípodas y se establece una dirección de ascenso (de la materia al espíritu por la vía de la renuncia) como el camino evolutivo, es por lo que la imagen de la desesperación de Moisés es poderosa, porque muestra que en la transgresión hay un alejamiento del camino recto que asciende a Dios, hay un camino que regresa al hombre a la materia. ¿Es así en la imagen de la caída de Lucifer?.

Es en la obediencia que se garantiza el orden social; la imagen de la renuncia a la riqueza o a cualquier deseo desmesurado y a todo lo pecaminoso que esto atrae a sí, sostiene a la sociedad moderada, sometida al poder del soberano. Hay una semejanza que une en lo imaginario a Dios y al soberano, de una manera bastante real y regulada por rituales y ceremonias de coronación, de transmisión de poderes, de investidura; lo que se está tratando de representar es un poder superior que es infundido o insuflado al soberano, se trata de la representación de una ligadura del rey con Dios que hace legítimo su mandato.

Los rituales de investidura en las democracias han perdido parte de los signos que constituyen la expresión de este poderoso símbolo, que antaño implicaba el "aperturar" canales de comunicación entre Dios y el soberano por medio de la utilización de filtros como aceites santificados, agua y prácticas (en muchos casos secretas) de los sacerdotes efectuadas en el momento de la coronación.

El poder del soberano, así, es legitimado como una extensión del poder de Dios, lo eterno entra así a lo temporal. Es así que la obediencia se convierte en un imperativo moral de primer orden para sostener al Estado. También se ve claramente a la soberbia como una amenaza de primer orden, originaria. La repetición de la traición original de los ángeles o de los intentos sediciosos de los dioses, es castigada y proscrita por medio de las historias que atañen a las consecuencias de la desmesura (hybris). De tal forma, el imperativo moral es reforzado, atándolo en lo temporal a la consecuencia del pecado, al castigo.

La construcción de las imágenes de perfección que hoy atestiguamos, el uso de medios como la eugenesia, señala en el sentido de una

\footnotetext{
${ }^{6}$ Se trata de una cita de: Glossa ordin. super Lev. c.1 prol. (I 214B); San Isidoro, Quaest. in Vet. Test, in Lev. c.1: ML 83, 321.
} 
perversión del poder, pues las imágenes de perfección se desvinculan de medios sobrenaturales, situando a lo perfecto (que es siempre finalidad) en el ámbito de poderes naturales y asequibles; se transfiere así la potencia divina que está fuera de este mundo, a una potencia temporal que está en este mundo, con lo que es posible alcanzar un estado de perfección final; se plantea como una posibilidad de aquí, pero siempre al futuro, la de rehacer el paraíso.

En efecto, hay una desvinculación del poder del soberano del de Dios, que de esta manera, establece una imagen de omnipotencia para sí, usurpándola de la divinidad. Hay en esta usurpación simbólica una patología evidente. En el contenido de los discursos radicales que hemos expuesto, sobresale la imagen de la renovación, del renacimiento, de la mejora humana a toda costa. El surgimiento del hombre nuevo, que ligamos en el imaginario occidental al arquetipo del héroe y su gesta, parece usurpar el poder de Dios, que radica precisamente en moira, el control del destino. Robado este derecho a la divinidad, ahora es tomado por el héroe, el que mueve la historia con el uso de su propio poder, hasta darle la forma que él con su voluntad ha proyectado.

El héroe, que toma así el control del destino, ejerce en lo temporal una atribución de lo eterno. El destino en manos del hombre poderoso, que por semejanza de atributos, apariencia, gesta, etc, es el héroe en el ámbito de las representaciones sociales, se rodea simbólicamente de los atributos de Dios, sobre todo de los de omnipotencia. Hay una embriaguez manifiesta en el ejercicio de ese poder que advierte Owen como síndrome de hybris y que atenaza a quienes detentan el poder, manifestándose más abiertamente en aquellos casos en los que se ejerce un poder con autoridad total.

La imagen de una ciudad y una sociedad perfecta tiene en su corazón a la soberbia. La desmesurada esperanza en la propia voluntad, que puede cambiar al mundo ${ }^{7}$, hasta hacerlo semejante a lo que se ha soñado, acercándola al deseo, como hemos visto, ha llevado a cometer los más crueles excesos. ¿Cuál es esa razón que está debajo de esa idea desmesurada de la voluntad?

La pulsión de poder, que se encuentra en el centro del imaginario de occidente (Narváez,
2012), quizás sea el motor profundo de la desmesura de las imágenes de un mundo perfecto. Como expresión de la voluntad y de la fuerza, se trata de una energía expansiva, abrasadora, que explota inflamándose. Esa es justamente la energía con la que el héroe inflama al pueblo, mostrándole el camino. Así, la falla del pueblo no se encuentra en la soberbia, sino en su ciega obediencia a la luz.

Como polillas deslumbradas por el brillo del héroe, así caminan las multitudes por el camino que éste ha trazado. No alcanzan a ver la diferencia, por el arraigo de la obediencia al soberano. Tal parece que este elemento del imaginario atenaza, esclaviza, eliminando toda la fuerza del juicio libre y crítico. Cuando es expuesto así el discurso de luz y de claridad, cuando ello se encuentra revestido por el poder del soberano, el juicio huye, la conciencia se somete.

Entonces es posible aceptar lo inaceptable y la enfermedad del soberano se convierte en una patología social. "Dar al césar lo que es del césar..." es una máxima que ya establece un rasero para el ejercicio de la crítica, que establece los límites de la obediencia en el imaginario de occidente. Al mismo tiempo instala una ética inamovible, basada en la religación a lo sobrenatural. Pero en la brillantez del héroe y su gesta el camino cambia, redirigiéndose a lo que es evidente, concreto, memorable y la lealtad es llevada para con él.

Es posible plantear que mediante las imágenes de perfección es que se consigue torcer esa lealtad y alentar a tomar como positiva una ética que rompe con los valores aceptables e instala los inaceptables. Revistiéndose de luz, es que las imágenes perfectas consiguen esto. Por la vía negativa, las imágenes distópicas, con las que se aterroriza a la masa y se le culpabiliza, actuarían como un acicate para "tomar por el buen camino", aquel que termina siendo la imagen de la utopía, de la luz.

De modo que la utopía y la distopía serían dos caras del mismo instrumento simbólico del poder. Atrapar mediante estos símbolos a la conciencia se llevaría a cabo a través de minar a la voluntad personal. Sea por la vía de inflamar a la multitud a través del arquetipo del héroe, o por el camino de la culpa y la vergüenza, el individuo termina siendo drenado de su energía personal por el poder. Tal parece ser la función de ese aparato simbólico.

\footnotetext{
${ }^{7}$ Por la vía negativa esto es visible en la culpabilización del ser humano por la "muerte de la tierra". Al mismo tiempo se trata de una culpa desmesurada.
} 
Una vía de libertad es necesaria frente a estas imágenes luminosas. Idénticamente frente a la oscuridad y la culpa de las imágenes de muerte y destrucción con las que se nos bombardea a diario. ¿Cuál puede ser este camino? Entre los extremos aparentes de esa tensión puesta ahí por los idealistas de una nueva humanidad, se abre una oposición de esa luz a la oscuridad, entre la utopía de una sociedad perfecta y la distopía de la desaparición de la tierra, se establecen dos aparentes contrarios. Vemos que no es tal esa supuesta oposición, podemos apreciar que hay además una vía entre esos extremos (que se encuentran del lado de la desaparición), que es anunciada por la lástima, animada por una conmiseración exacerbada.

Tal parece que el otro camino que se toma frente a los que no parecen encajar en nuestras ciudades perfectas es el de una compasión sin medida, la misma que ha animado a los proyectos de construcción de inatalaciones para la reclusión, establece un tratamiento para las personas vulnerables que puede llegar hasta el extremo de anularles como personas. Considerándolos como incapaces de llevar una vida "normal", establece un cerco de protección, aparta, aísla, y asume para la discapacidad un sentimiento de frustración e impotencia.

Si la pulsión de poder que anima a los proyectos de limpieza social se caracteriza por su expansividad, por ser una energía que va hacia afuera; la energía que animaría a los movimientos centrados en la exacerbada conmiseración estarían, también centrados en la pulsión de poder, pero de un poder implosivo, que palidece, frente a un poder expansivo que es rubicundo. Entonces vemos que hay una oposición que se establece sobre el eje del poder (que se expande, que se contrae), que va desde la invisibilidad hacia la lástima.

Esta oposición parece estar presente en el ámbito de nuestros discursos e imágenes alrededor de la ciudad perfecta. Quizás sea necesaria una vía intermedia, un justo medio entre la ceguera y la conmiseración. La búsqueda de la dignidad de la persona puede ser un camino que deberíamos caminar para buscar esta vía intermedia. $\mathbf{C}$

\section{Referencias bibliográficas.}

Acaso López-Bosch, M. (2009). El lenguaje visual. México: Paidós.
Bacon, F. (1628). New Atlantis, en la segunda edición de: Sylva sylvarvm: or A naturall historie. In ten centvries. Londres: J.H. para William Lee y Turkes Head. Versión en español: La Nueva Atlántida, en línea http://www.biblioteca.org.ar/libros/130891.pdf [31/03/2018].

Carmona, G. (2015). Ciudad imaginaria y sociedad virtual. Las redes sociales virtuales como medio para el análisis de los imaginarios urbanos. Guadalajara: Universidad de Guadalajara-Universidad Autónoma de Coahuila.

Cassin, B. (2008). Googléame. La segunda misión de los Estados Unidos. Buenos Aires: Fondo de Cultura Económica.

Darwin, Ch. (1859). On the Origin of Species by Means of Natural Selection, or the Preservation of Favoured Races in the Struggle for Life. Londres: John Murray. (Versión en español: El origen de las especies, España: Ediciones Fenix, 2015).

De Aquino, T. (1993). Summa de teología parte I-II. Madrid: Biblioteca de Autores Cristianos, (c. 1265-1274).

Galton, F. (1869). Hereditary genius, an inquiry into its laws and consequences, Nueva York: D. Appleton. (Versión en español (textos seleccionados): Herencia y eugenesia, Madrid: Alianza, 1988). Hobsbawm, E. (1987). The Age of Empire 1875-1914, Londres: Weidenfeld and Nicolson. (Versión en español: La era del Imperio, Buenos Aires, Editorial Crítica, 1998). Lamarck, J. (1809). Philosophie zoologique. (Edición en español: Filosofía zoológica. Barcelona: Edición facsimilar de la edición de 1910 por Editorial Alta Fulla-Mundo científico, 1986.

Laughlin H. (1923). The Second International Exhibition of Eugenics. Baltimore: William \& Wilkins Co.

Le Corbusier. (1953). El Modulor. Buenos Aires: Poseidon.

Malthus, T. (1798). An Essay on the Principle of Population, Londres: J. Johnson. (Versión en español: Primer ensayo sobre la población. Madrid: Alianza Editorial, 1995).

McDougall, W. (1927). An experiment for the testing of the hypothesis of Lamarck. British Journal of Psychology, 17, pp. 267- 304.

McDougall, W. (1930). Second Report on a Lamarckian Experiment. British Journal of Psychology, 20, pp. 201-218.

McDougall, W. (1938). Fourth Report on a La- 
marckian Experiment. British Journal of Psychology, 28, pp. 321-345.

Morris, A. E. S. (1984). Historia de la forma urbana. Barcelona: Gustavo Gili.

Narváez, A. (2012). Ciudades inimaginables. El imaginario hegemónico tras la globalización, México-Barcelona: UANL-Universidad Politécnica de Cataluña.

National Security Council. National Security Study Memorandum NSSM 200: Implications of Worldwide Population Growth for U.S. Security and Overseas Interests, (The Kissinger Report). Washington: Consejo de Seguridad Nacional de los Estados Unidos, 10 de diciembre de 1974.

Owen, R. (2010). En el poder y en la enfermedad: Enfermedades de jefes de Estado y de gobierno de los últimos cien años. Madrid: Siruela.

Padilla Muñoz, A. (2010). «Discapacidad: contexto, concepto y modelos», 16 International Law, Revista Colombiana de Derecho Internacional, 381-414.

Platón. La República. (2012). (Traducción para la versión en español de J. M. Pabón y M. Fernández-Galiano. Madrid: Alianza Editorial).

Sánchez M. (2017). «Salvador Allende, esterilización de alienados y debate eugénico chileno», Izquierdas, 35, septiembre, pp. 260-286.

Spencer, H. (1876). First Principles of a New System of Philosophy. Nueva York: D. Appleton and Company.

Spencer, H. (1888). Social Statics, Nueva York: D. Appleton and Company, 1888.

Valera, L. (2018). Contra los modelos inalcanzables. Perfección, tecnología y sociedad. Sociología y Tecnociencia, [S.1.], v. 8, n. 1, p. 1-16, enero. En línea: <https://revistas.uva.es/index.php/ sociotecno/article/view/1702>. [05/04/2018].

Villela Cortés, F., Linares Salgado, J. (2011). «Eugenesia. Un análisis histórico y una posible propuesta», Acta Bioethica 17 (2): 189-197. 